\title{
Trabalho de campo como metodologia de ensino: relato de experiência em Geografia
}

\author{
Fieldwork as a teaching methodology: the experience with Geography \\ MONTE$^{1}$, L. A.; ALBUQUERQUE 2 , E. L. S. \\ lucasmonte-geo@hotmail.com
}

\begin{abstract}
Resumo
O espaço geográfico possui elementos que apresentam suas compreensões baseadas em análises diversificadas e aprofundadas, contribuindo para o processo de construção de teorias, das quais são originados conceitos e fundamentos básicos. Nesse sentido, a Geomorfologia surge como a ciência que estuda as formas de relevo, com suas respectivas teorias e conceitos. Para verificação das formas de relevo, o Trabalho de Campo se configura como principal recurso metodológico a ser utilizado nos diferentes níveis de ensino, seja ele básico ou superior, no momento em que a prática de campo proporciona o contato direto entre o pesquisador e o objeto de estudo. Nesse sentido, o presente trabalho tem como objetivo principal o relato de experiência de um Trabalho de Campo realizado em municípios do Piauí e Ceará, com o intuito de verificar in loco a aplicação de conceitos da ciência geomorfológica. Para tanto, revisões bibliográfica foram realizadas a fim de se obter um maior suporte teórico, tal como observações e análises realizadas durante a prática de campo. A partir disso, constata-se a necessidade dos Trabalhos de Campo, com suas respectivas descrições e caracterizações da paisagem, ou seja, proporcionando uma maior relação entre sociedade e natureza.
\end{abstract}

Palavras-chave: Geomorfologia. Ensino-aprendizagem. Paisagem.

\begin{abstract}
The geographical area has elements that present their understandings based on diverse and in-depth analyzes, contributing to the process of constructing theories, of which originate concepts and fundamentals. In this sense, Geomorphology emerges as the science that studies the forms of relief, with their theories and concepts. For verification of landforms, the Fieldwork is configured as main methodological resource to be used at different levels of education, whether basic or higher, at the time the field practice provides direct contact between the researcher and the object of study. In this sense, the present work has as main objective the experience report of a Field Study conducted in Piauí and Ceará municipalities, in order to verify on the spot the application of concepts of geomorphological science. Therefore, literature reviews were conducted in order to obtain a greater theoretical support, such as observations and analyzes carried out during the field practice. From this, there has been the need for field work, with their descriptions and landscape characterizations, ie, providing a greater relationship between society and nature.
\end{abstract}

Keywords: Geomorphology. Teaching and learning. Landscape

\section{INTRODUÇÃO}

O espaço geográfico possui elementos que apresentam suas compreensões baseadas em análises diversificadas e aprofundadas, contribuindo para o processo de construção de teorias, das quais são originados conceitos e fundamentos básicos. Com isso, percebe-se uma integração entre conceitos das mais diversas ciências, ou seja, a interdisciplinaridade verificada no processo de análise e compreensão do espaço geográfico e seus elementos. 
Nessa perspectiva, se verifica a contribuição de elementos para uma análise do espaço, por intermédio dos procedimentos geográficos, dentre os quais citam-se: escala, extensão, frequência, distância e proximidade (MOREIRA, 2007). Desta forma, estes elementos contribuem para os diversos estudos, não só da geografia, à medida que organizam o entendimento da realidade em suas diversas alterações.

Ainda assim, para análises do espaço geográfico, Andreis (2012) elenca os conceitos e fundamentos necessários, os quais dividem-se em categorias e temas, que orientam a interpretação da realidade por meio do: território, paisagem, lugar, região e espaço. Dentro destas categorias, inserem-se abordagens que remetem aos dois campos de estudos da Geografia, a saber: Geografia Humana e Geografia Física. Entretanto, ressalta-se a importância da utilização da categoria paisagem nas análises físicas do ambiente.

Dentro do campo de estudo da Geografia Física há ciências que delineiam a caracterização natural da paisagem, descrições estas que ocorrem entre áreas afins, com inter-relações em seus respectivos conceitos. Dentre elas, citam-se: Climatologia, Pedologia, Geologia, Hidrografia, Biogeografia, Geomorfologia, entre outras.

Dessa maneira, a Geomorfologia se insere no campo cientifico geográfico. De acordo com Christofoletti (1980), esta ciência estuda as formas de relevo, e que estas formas seriam a expressão espacial da superfície terrestre, passível à atuação dos demais elementos da paisagem, elementos estes que contribuem para o modelado das formas da superfície.

A partir da atuação de tais elementos, percebe-se a aplicação do conceito de sistema nos estudos geomorfológicos, o qual "pode ser definido como o conjunto dos elementos e das relações entre si e entre os seus atributos" (CHRISTOFOLETTI, 1980, p. 1), ou seja, as formas do relevo terrestre estão submetidas às ações que as moldam como característica de um sistema aberto, com interferência de grande parte dos elementos compositores da paisagem.

Quanto à interação entre os elementos e propriedades inseridas em um sistema, ressalta-se que este pode ser classificado como sistema isolado ou sistema não-isolado, no qual, neste último, verifica-se a existência de sistema não-isolado fechado ou aberto (CHRISTOFOLETTI, 1980). É importante destacar que nestes dois tipos de sistemas, seja ele fechado ou aberto, pode haver trocas de energia e/ou matéria, proporcionando uma ciclagem no modelado das diferentes feições e propriedades da superfície terrestre.

Para verificação das feições geomorfológicas, suas propriedades e inter-relação de forma integrada com os demais elementos que compõem a paisagem, torna-se pertinente a importância da realização de Trabalhos de Campo. Essa prática "constitui uma metodologia que engloba a observação, a análise e a interpretação de fenômenos no local e nas condições onde eles ocorrem 
naturalmente" (NEVES, 2015, p. 15). Nesse contexto, acrescenta-se ainda que o Trabalho de Campo deve ser feita com observação de maneira empírica e atenta ao objeto de estudo, para posteriores correlações entre fenômenos identificados em associação aos conceitos verificados na literatura especializada (SILVA et al., 2008).

Nesse sentido, através do Trabalho de Campo, os conceitos da ciência geomorfológica podem ser percebidos a partir de suas aplicações práticas, demonstrando assim a relação entre formas de relevo e as demais estruturas que compõem a paisagem, ou seja, verificação in loco da relação entre os sistemas - abertos ou fechados.

O Trabalho de Campo consiste numa atividade utilizada em diversos campos científicos e que pode ser adequada a distintos níveis da educação, passando pelo ensino básico e chegando ao ensino superior (NEVES, 2015). Em ambos os níveis de ensino, constata-se como principal influência a possibilidade de interação entre pesquisador (estudantes) e objeto de estudo (VIVEIRO; DINIZ, 2009), salientando, também, a importância do estreitamento entre aluno e professor, tornando mais dinâmico o processo de ensino-aprendizagem.

Ainda de acordo com Neves (2015), verifica-se que para a realização da prática de campo deve haver organização das atividades, tais como: preparo técnico de alunos e professores; elaboração de um programa de trabalho, contendo as principais etapas e detalhamentos da prática e; seleção de equipamentos necessários para coleta e análise de dados.

Nesse sentido, o presente trabalho apresenta análises e compreensões conceituais verificadas in loco com direcionamentos ao ensino superior, haja vista a necessidade de aproximação entre teoria (verificada em bibliografias especializadas) e prática, bem como maior aproximação entre aluno e professor, os quais se configuram como quesitos importantes a serem seguidos tanto no ensino básico quanto no ensino superior, a fim de maiores aprendizagens.

Para tanto, com a proposta de analisar a realidade física do espaço geográfico por meio da teoria e prática, o presente trabalho tem como objetivo relatar uma experiência de atividade de campo (em municípios do Piauí e Ceará) realizada como pré-requisito para obtenção de nota parcial na disciplina de Geomorfologia II, do Curso de Geografia, da Universidade Federal do Piauí (UFPI).

\section{METODOLOGIA}

Ao consistir numa fase de suma importância, o procedimento metodológico utilizado na realização da presente pesquisa baseou-se em revisão bibliográfica sobre a temática central, a qual 
serviu como suporte teórico na utilização do método da Análise Ambiental (ROBAINA et al., 2009).

Dessa forma, o Trabalho de Campo foi realizado a fim de se obter dados in loco das paisagens, sendo verificadas as feições geomorfológicas. As atividades ocorreram em municípios dos estados do Piauí e Ceará. Diante disso, um roteiro de campo foi concebido anteriormente, o qual continha o mapeamento dos pontos de visitas a serem feitas, sequenciados pelas análises.

O Trabalho de Campo, que ocorreu no mês de julho de 2016, seguiu o seguinte roteiro, com paradas nos municípios de: Campo Maior-PI, Pedro II-PI, Tianguá-CE e Ubajara-CE. A Figura 01 ilustra as etapas metodológicas da atividade realizada.

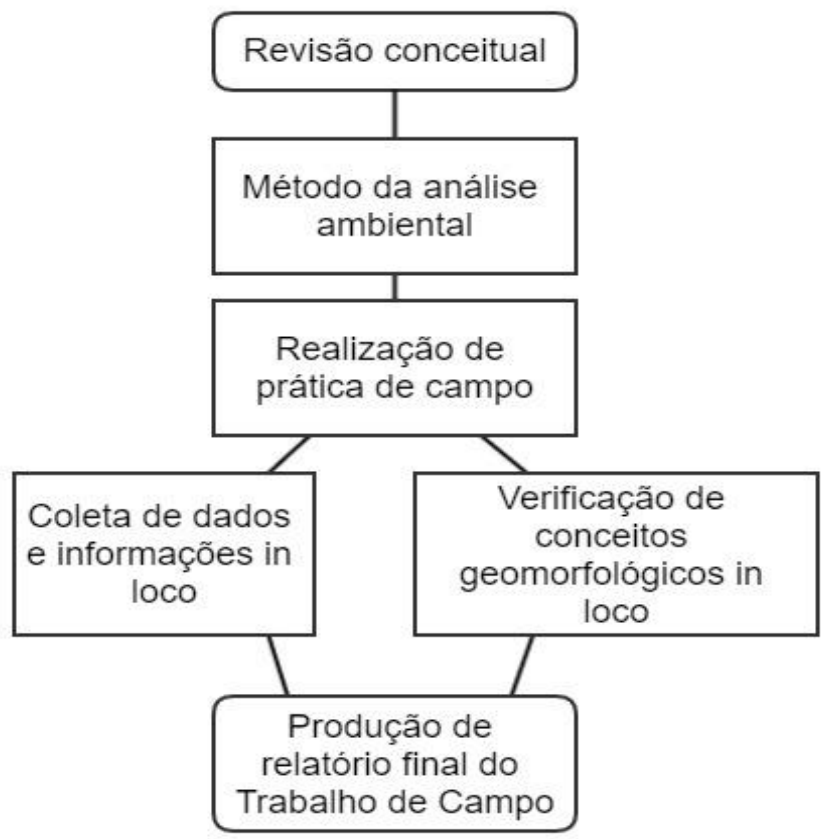

Figura 01. Procedimentos metodológicos da pesquisa. Fonte: Monte (2016).

\section{RESULTADOS E DISCUSSÃO}

O primeiro ponto de análise teve as coordenadas $\mathrm{x}=809.461$ e $\mathrm{y}=9.461 .948$ (Sistema UTM / Datum Sirgas 2000). Esse ponto situa-se a uma distância aproximada de $5 \mathrm{~km}$ da Sede do município de Campo Maior-PI. Nessa parada foram observados os dados e aspectos solicitados na ficha técnica de campo.

No tocante à geologia local, verificou-se que a unidade litoestratigráfica consiste na Bacia Sedimentar do Parnaíba. Em complemento a isso, foi possível perceber, através dos mapas (Figura 02), a litologia predominante, constatando-se a posição na Formação Longá, que é caracterizada por siltitos e folhelhos. 


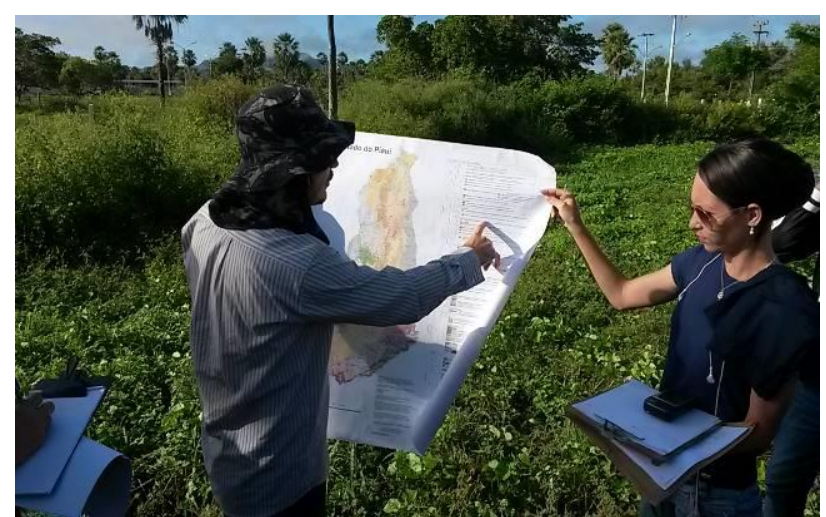

Figura 02. Análise sendo realizada no primeiro ponto de parada, no município de Campo Maior-PI, durante Trabalho de Campo. Fonte: Monte (2016)

No que diz respeito à geomorfologia, foi possível observar um relevo plano e suavemente ondulado, com altitude média de $125 \mathrm{~m}$. Com isso, verificou-se o favorecimento ocupacional do espaço pela população. As características hidrográficas surgem através da Bacia Hidrográfica do Parnaíba, possuindo a sub-bacia do Rio Longá como destaque.

Ainda neste ponto, observou-se a presença de solo fértil, com presença de carnaúbas e plantações diversas, verificando ainda a presença de latifúndios e, consequentemente, uma significativa ação antrópica. Com isso, foi possível perceber que a terra neste ponto do Trabalho de Campo não possui valor cultural, e sim apenas econômico, com criação de gado e prática da agricultura.

O segundo ponto de análise teve as coordenadas $x=225.454$ e y=9.509.792 (Sistema UTM / Datum Sirgas 2000). Nesse ponto, foi possível verificar uma mudança no relevo, o qual possui altitude média de 560 m. O local de parada foi às margens da Rodovia Federal (BR - 404), próximo ao município de Pedro II-PI e nas proximidades do Açude Joana.

Vale salientar que o açude mencionado (Figura 03) é consequência do barramento das águas do Rio Corrente, afluente do Rio Longá, que pertence à Bacia Hidrográfica do Rio Parnaíba. Ainda nesse ponto foi possível observar um afloramento rochoso de diabásio, o qual é composto por plagioclásios e piroxênios. Esse afloramento trata-se de uma rocha cristalina intrusiva, sendo essa intrusão em formato de dique. 


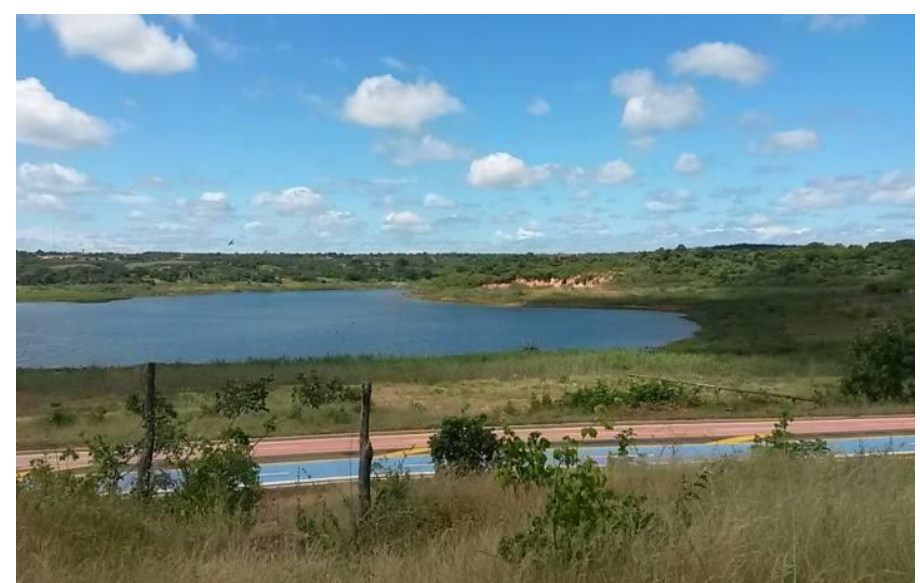

Figura 03. Vista parcial do Açude Joana, na entrada do município de Pedro II-PI. Fonte: Monte (2016)

A fim de preenchimento da ficha técnica de campo, a geologia do ponto insere-se na Bacia Sedimentar do Parnaíba como unidade litoestratigráfica. No tocante à litologia, há a presença de diabásio. As rochas do afloramento de diabásio possuíam como características estruturais um intemperismo físico em estado avançado, sendo isso percebido através da fragilidade das amostras de rochas coletadas em campo. Ressalta-se ainda que o intemperismo verificado no local configurase, predominantemente, do tipo físico, fato este explicado devido à influência exercida pela climatologia local. Sobre isso, ressalta-se que o clima do local é caraterizado por possuir temperaturas amenas, devido ao tipo climático tropical de altitude verificado na região.

O ponto seguinte para análise consistiu em um mirante localizado no município de Pedro IIPI (coordenadas x=227.931 e y=9.513.668 - Sistema UTM / Datum Sirgas 2000). Esse ponto denomina-se "Mirante da Santa", devido à forte presença do sentimento religioso no município, tornando-se, então, local de visitação de turistas e moradores para realização de práticas religiosas. Nessa parada foi possível observar a estrutura geomorfológica do município de Pedro II-PI, verificando a presença de morros testemunhos no segundo plano da foto (Figura 04). Observa-se também a ocorrência de blocos rochosos com característica estrutural em prisma, o qual compõe um aspecto geológico pouco comum da Formação Cabeças. 


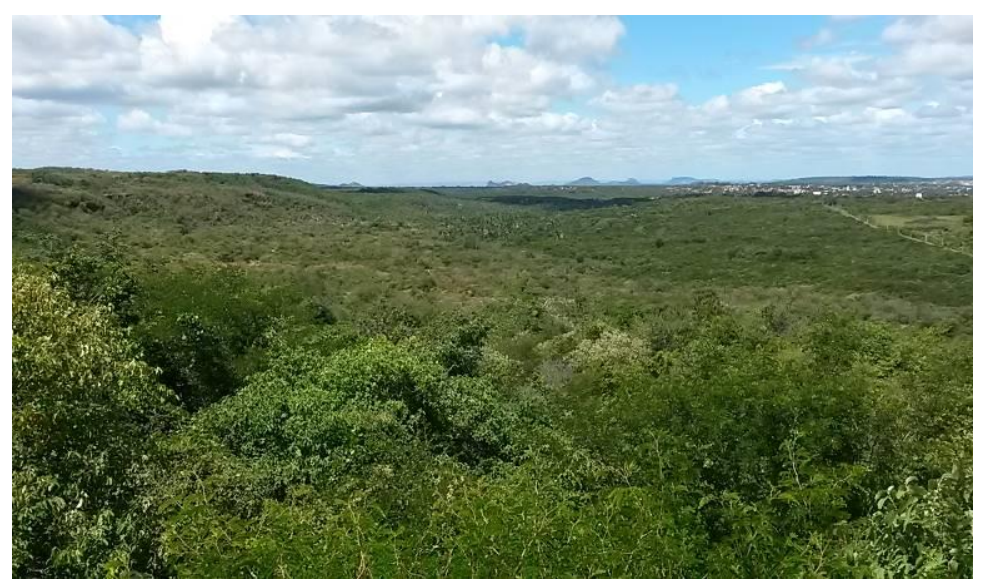

Figura 04. Vista a partir do Mirante da Santa, no município de Pedro II-PI. Fonte: Monte (2016)

O ponto de parada seguinte ocorreu ainda no município de Pedro II-PI (coordenadas $\mathrm{x}=228.334$ e $\mathrm{y}=9.520 .854$ - Sistema UTM / Datum Sirgas 2000), em um local situado numa estrutura geomorfológica do tipo Cuesta. Esse ponto consiste no "front secundário elaborado no reverso regional da Ibiapaba" (SOARES E SILVA et al., 2014, p. 1), denominado como "Morro do Gritador" (Figura 5). No tocante à geologia, foi possível perceber que este se insere em uma porção de contato geológico da Formação Cabeças com a Formação Pimenteiras, com altitude de 710 m.

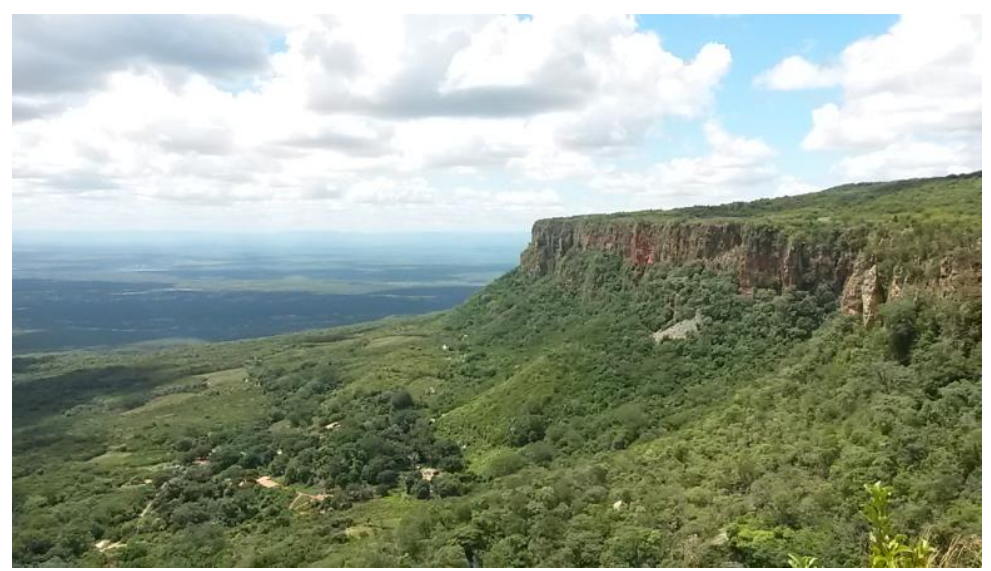

Figura 05. Vista parcial do Front e Reverso imediato regional da Ibiapaba - Morro do Gritador. Fonte: Monte (2016)

Nessa parte do reverso regional da Ibiapaba, verificou-se a presença da falha geológica denominada Sobral-Pedro II, a qual teve sua formação no Ciclo Transbrasiliano (SCHOBBENHAUS; NEVES, 2003). Esta falha é formada predominantemente por arenito, sendo verificada também grande presença de grupos vegetacionais no interior de sua estrutura, favorecidas por um conjunto de aspectos ambientais propícios (Figura 6). 


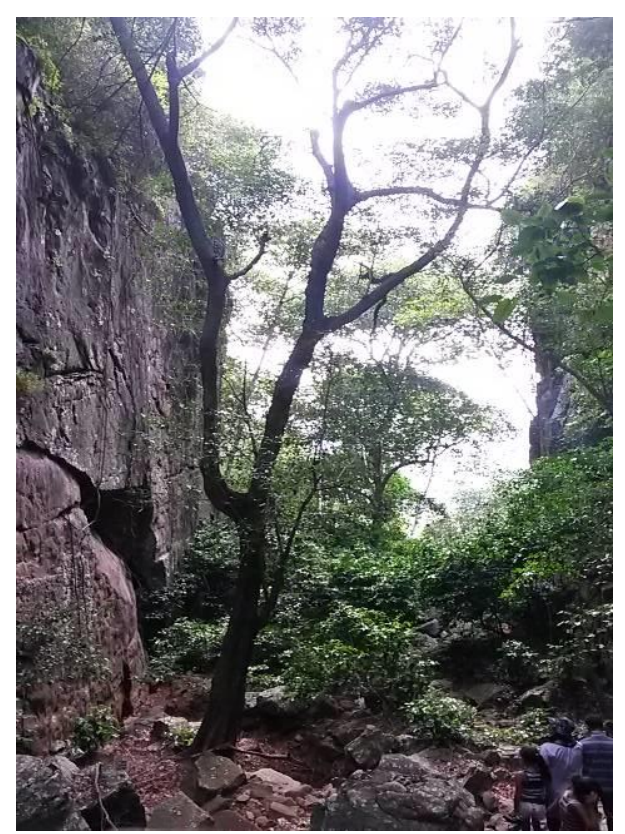

Figura 06. Vista parcial da Falha geológica Sobral-Pedro II. Fonte: Monte (2016)

Após observações e análises realizadas no reverso regional da cuesta da Ibiapaba, a parada seguinte ocorreu na área de divisa entre os estados do Piauí e Ceará. No tocante à unidade litoestratigráfica, foi possível observar a presença da Formação Pimenteiras em área de contato com a Formação Serra Grande, sendo que esta última estrutura se caracteriza por ser a mais antiga dentre as formações da Bacia Sedimentar do Parnaíba (coordenadas x=251.955 e y=9.566.720 - Sistema UTM / Datum Sirgas 2000).

Para finalizar, o último ponto de análise ocorreu no Parque Nacional de Ubajara, estado do Ceará. Este Parque situa-se na Cuesta da Ibiapaba, mais especificamente na borda oriental da Bacia Sedimentar do Parnaíba. Quanto à caracterização climática, foi possível concluir que este setor possui um clima tropical típico de altitude, com elevados índices pluviométricos e temperaturas amenas em boa parte do ano.

\section{CONSIDERAÇÕES FINAIS}

Ao analisar o exposto anteriormente, corrobora-se que o trabalho de campo configura-se como uma atividade primordial no processo de construção do conhecimento, ressaltando essa atividade como uma metodologia que proporciona aplicações práticas de conceitos e fundamentos, na perspectiva de materializar no campo os conceitos e teorias.

Com isso, a partir da realização da prática de campo, foi possível verificar conceitos pertinentes à disciplina de Geomorfologia II, do Curso de Geografia da Universidade Federal do Piauí (UFPI), a partir da observação da paisagem com seus respectivos elementos. Ainda assim, 
ressalta-se que os conceitos verificados in loco possuem uma essencial importância para a compreensão do modelado terrestre e suas respectivas formas.

Portanto, o trabalho de campo realizado nos municípios aqui citados se mostrou enriquecedor, através da observação de elementos constituintes do espaço geográfico, inserindo-se as estruturas geológicas e geomorfológicas como peças fundamentais na manutenção de todo o sistema, tendo em vista que a natureza é um todo integrado.

\section{REFERÊNCIAS}

ANDREIS, Adriana Maria. Ensino de Geografia: Fronteiras e horizontes. Porto Alegre: Compasso Lugar-Cultura: imprensa Livre, 2012.

CHRISTOFOLETTI, Antônio. Geomorfologia. 2. ed. São Paulo: Edgard Blucher, 1980.

MOREIRA, Ruy. Conceitos, categorias e princípios lógicos para o método e o ensino de geografia. Pensar e ser em geografia: ensaios de história, epistemologia e ontologia do espaço geográfico. São Paulo: Contexto, p. 105-118, 2007.

NEVES, Karina Fernanda Travagim Viturino. Os trabalhos de campo no ensino de geografia: reflexões sobre a prática docente na educação básica. Ilhéus: Editus, 2015. Disponível em: <http://www.uesc.br/editora/sumarios/os_trabalhos_no_campo.pdf> Acesso em: 12 jul. 2016.

ROBAINA, Luís Eduardo de Souza; TRENTIN, Romário; NARDIN, Dionara de; CRISTO, Sandro Sidnei Vargas de. Método e técnicas geográficas utilizadas na análise e zoneamento ambiental. Revista Geografias. Belo Horizonte, v. 5, n. 2, p. 36-49, jan./jun. 2009.

SCHOBBENHAUS, Carlos; NEVES, Benjamin Bley de Brito. A Geologia do Brasil no contexto da Plataforma Sul-Americana. In: BIZZI, L. A; SCHOBBENHAUS, Carlos; VIDOTTI, R. M.; GONÇAlveS, J. H. (Org.). Geologia, Tectônica e Recursos Minerais do Brasil. Brasília: CPRM, 2003. Disponível em: < http://cprm.gov.br/publique/media/capI-a.pdf> Acesso em: 13 jul. 2016.

SILVA, Kássia Nunes da; ALVES, Lidiane Aparecida; LOPES, Michelly de Lourdes Lopes. A importância de se praticar o trabalho de campo na ciência geográfica. Revista A MARgem Estudos. Uberlândia, n. 1, p. 10-19, jan./jun. 2008.

SOARES E SILVA, Yago Lins; NETO, José Soares Fernandes; LIMA, Iracilde Maria de Moura Fé. O Morro do Gritador e as opalas, Pedro II (Piaui): aspectos da geologia e do relevo local. In: Jornada de Estudos de Geografia Física, 2, Teresina, Piauí. Anais... Teresina, Piauí, 2014.

VIVEIRO, Alessandra Aparecida; DINIZ, Renato Eugênio da Silva. Atividades de campo no ensino das ciências e na educação ambiental: refletindo sobre as potencialidades desta estratégia na prática 
escolar. Revista Ciência em Tela. Rio de Janeiro, n. 1, v. 2, 2009. Disponível em: <http://www.cienciaemtela.nutes.ufrj.br/volume2/1/sala_de_aula1.html> Acesso em: 12 jul. 2016.

Recebido em: 14/08/2016

Aceito para publicação em: 01/10/2016 